\title{
The Construction of the Long-term Mechanism of the Ecological Environmental Governance in Our Country
}

\author{
Yu Ding \\ School of Literature, Law and Economics \\ Wuhan University of Science and Technology \\ Hubei Wuhan, China 430065
}

\author{
Chengcheng Zou \\ School of Literature, Law and Economics \\ Wuhan University of Science and Technology \\ Hubei Wuhan, China 430065
}

\begin{abstract}
The ecological environment is the basis for the living and development of human. With the appearance of ecological issues, the ecological governance has become the focus concerned by the country and the public. The idea of sustainable development requires us to establish the long-term mechanism for the treatment of ecological environment pollution which is also the inevitable choice for ecological governance of the government. This paper sets out from five major aspects including the policies, power, laws, governance and supervision and combines with the current situation of ecological environmental governance of our government based on the analysis of domestic and foreign research summary, from the aspects of dynamic mechanism, incentive mechanism, monitoring mechanism, execution mechanism and safeguard mechanism of ecological environmental governance to discuss the construction of the target system and long-term mechanism of ecological environmental governance of the government.
\end{abstract}

Keywords-ecological environment; government governance; governance effect; long-term mechanism

\section{INTRODUCTION}

From the Scientific Outlook on Development to the overall layout of "Five in One", from the "new pattern of modernization construction for the harmonious development of human and the nature" brought up in the Third Plenary Session of the 18th CPC Central Committee to the "Green Development" put forward in the Fifth Plenary Session of the 18th CPC Central Committee, the status of ecological environment construction of our country is continuously promoting and the reform is also continuously deepening. In the multi-subject of the ecological environment construction, the government plays the most important role and leads the multi-subject to conduct the process of ecological governance and construction. The ecological environmental governance has also turned into the kind of public issues and political issue from the natural science.

\section{RESEARCH SUMMARY ON THE DOMESTIC AND FOREIGN ECOLOGICAL ENVIRONMENTAL GOVERNANCE}

The eco-political theory ascends the environment to the political level and again combs the relations among the nature, society and politics which causes the change of political values; the public governance theory emphasizes on the publicity of governance to lay the foundation of the public action system; the externality theory analyzes the effects in ecological behaviors of the government from the perspective of economics and analyzes the reasons of the occurrence of "freeriding" behaviors and governance costs transferring under the effects of ecological behaviors and impacts of negative externality which provides the theoretical foundations for the formulation of coping mechanism of ecological environmental governance issues for the government.

\section{A. Foreign Research Summary}

The foreign ecological environmental governance is mainly dominated by the government and the economic adjustment is the main governance measure. Rachel Carson's Silent Spring (1962) firstly showed the correlation level between ecological environment and human society to the public which caused the concern of the public on ecological environmental protection. Meadows (1972) pointed out the crisis relations between social development and natural environment in the Limits to Growth which urged human to seek for the solutions and again introduced the issue of ecological environment into the view widely concerned by countries in the world.

\section{B. Domestic Research Summary}

The domestic scholars also launch plenty of researches on the ecological environmental governance of the government according to the concrete national conditions of our country. Zhou Wencui and Liu Jingwei (2016) pointed out that the pursuit of interest on current economy, unbalance of rights and liabilities on concept level and absence of systems are all the main reasons which causes the illusive establishment of ecological responsibilities of the government[1]. Yu Chaowen (2016) thought that if the government wants to realize the good governance of ecological environment, it must change the governance ideas and establish the shared governance network and the institutional guarantee mechanism to form the benign interaction relations among governance bodies[2]. Wang Qian (2011) advocated to perfecting the accountability system of various bodies diversification: enhance and enlarge the accountability functions of deputy to the NPC, judicial 
departments, citizens and news consensus so as to perfect the domestic ecological environment liability system[3].

On the research of long-term mechanism for ecological governance: Ye Jin and Zhou Hongbin (2009) analyzed the necessity to construct the long-term mechanism for the rural ecological environment protection from the perspectives of agriculture, rural ecological environment resources and the rural ecological environmental governance[4]; Lin Jiancheng and $\mathrm{An} \mathrm{Na}$ (2015) emphasizes that the long-term mechanism for ecological governance is the inevitable choice according with the value of times from the perspective of the relations between the modernization of national governance system and the long-term mechanism for ecological governance[5]; Zeng Xiangyun (2005) analyzed the significance of the long-term mechanism for ecological environment protection[6]; Peng Xiaoyan (2014) discussed the establishment of the long-term mechanism for ecological environment protection from the perspective of the relations between sustainable development of tourism and the environment protection through four aspects of eco-compensation subjects, objects, compensation channels and compensation strength[7]; Huang Jie and Zhang Zhanbo (2015) thought that the overall planning of interest demands, deep integration of resources and the realization of ecological long-term governance are the essential measures to solve the ecological issues[8].

\section{SHORT-TERM ISSUES OF ECOLOGICAL ENVIRONMENTAL GOVERNANCE OF THE GOVERNMENT}

The ecological environment has the features of integrality and unboundedness. The human life is interlocking with joined interests. The current national ecological environmental governance still has the short-term coping feature of "from pollution to governance" and "from finding to governance". There are still issues such as lack of ecological value unclear rights and obligations division, relationship dislocation between government and enterprise, imperfect legal system and incomplete supervision network and those governance loopholes are hard to meet the long-term proceeding of ecological governance.

\section{A. Lack of Government Ecological Values}

The value is basis of behaviors. The ecological values have significant basic functions to the ecological environmental governance of the government and are also the precondition for the government to realize ecological governance[9]. Since the reform and opening up, the extensive mode of economic growth and development patterns of "high investment and low efficiency" cause the government to fall into the "secondary ecology" idea of "only GDP" in the aspect of ecological governance. The government ignores the value of ecology in the social development processes, has lack of the supervision on ecological responsibilities and the publicity and education of citizens and has the unstable foundation of ecological governance. Therefore, the ecological governance is hard to be continued.

\section{B. Vague Setting of Government Ecological Functions and Responsibilities}

For the publicity feature of ecological, it is hard to be effectively supplied in the free market mechanism where the market plays a decisive role. And the overuse caused by "market failure" and thought of "free ride" will be more likely to result in the "tragedy of the commons"[10]. The environment protecting management mechanism dominated by the blocks has produced many problems: local government focusing on development, ignoring environmental protection and severe local protection; the government intervenes in the monitoring, supervision and law enforcement of environmental protection administrations and fabricates the ecological responsibilities of government. The static organizational design can't cope with the changes of environment and the lack of action basis of environmental protection administration will cause the lack of management authority and each department will argue back and forth over trifles and the problems can't be completely solved.

\section{Mishandling of Relations between Government and Enterprises}

The government and enterprises are the two subjects on the same profit chain who are trying to approach with each other through economic interests. Both the cooperation of government and enterprises and the government supervision are indispensable. Originating from the blind pursuing of GDP, some local governments provide convenience for the enterprises in policies and systems. The local development competition and local protection cause the enterprises to be lost in the dense fog of the ambiguous powers and responsibilities which brings huge crisis to the local environment and public health. The government assumes the role for contamination governance but losses the dominant position of contamination control in the ecological governance, ignores the target of serving the people, insists on the GDP theory and carries out the policy of economy first.

\section{Defective Legal System Construction}

The foundation of legal difficulties for ecological environment lies in the departure of legislation ideas and lack of principles: the conventional thinking of economy first ignores the noumenon values of ecological environment and the legal system also becomes a mere scrap of paper. The differentiations between "soft law" and "hard law" directly weaken the status of ecological environment protection. The environmental protection act is seen as "process law" and "appearance law" with no authorities. The subjects of law enforcement are driven by interests towards the local protection and failure to abide by laws. The failure of judicial accountability will cause the lack of punishment and encourage the pollution behaviors.

\section{E. Defective Social Supervision Network}

There exists in the national supervision network of ecological environment pollution that: poor environment publicity and education, blocked report channels and inappropriate relations between media and the government. The government lacks of the abilities for timely concern and 
supervision, therefore, the social supervision is needed to motivate the supervision power of citizens and media to find and solve the problems timely. Ensuring the channels unblocked is the preparation work for government to motivate the social subjects to participate in the governance while handling the relations between the government and news media is another important promise for ecological environmental governance.

\section{ESTABLISHMENT OF LONG-TERM MECHANISM FOR ECOLOGICAL ENVIRONMENTAL GOVERNANCE OF GOVERNMENT}

The governance and protection of ecological environment need maintenance and insistence. Establish the values concept, policies, execution, feedback and interaction scheme mechanism and take the "green development" as target, optimize and perfect the ecological environmental governance of the government to provide the mechanism guarantee of policy and long-term effect for the intergenerational living and development.

\section{A. Establishment of the Dynamic Mechanism Promoting the Ecological Environmental Governance}

Pay attention to green development and establish the values concept and multiple investment mechanism. The government should change the values concept to take the ecological values as core and insist on "green development" theory to play the role of guiding and complying with the socialist construction law exploration and realize the unification including development and protection. Pay attention to the comprehensive investment of human resources, properties and materials. On one hand, improve the professional requirements of the government functionaries in the government environmental protection departments and guide the ecological governance through the establishment of professional teams; on the other hand, build the communication platform and increase the strength on ecological governance and protection. Broaden the financing channels, innovate ecological governance technology, perfect the materials and equipment to promote overall and local ecological development and accord development of our country.

\section{B. Establishment of the Interest Coordination Mechanism of Ecological Environmental Governance}

Clear the division of organizing functions and responsibilities and improve the coordination mechanism of organizing functions and powers. Clear the function and power division of local environmental protection administrations and endow the environmental protection administrations with the powers of commanding, coordinating and domination for human resources, properties and materials. Set the unified supervision organizations to realize the environmental vertical management system. Play the functions of overall planning, dispatching and coordination of the central government to realize the overall planning.

Complete the enforcement basis and implement the guarantee and coordination mechanism. Methodize and systematize the administrative management system, environmental protection system, governance coordination system and pollution control index system involved in the process of ecological environmental governance to provide system management and services for the ecological environmental governance of the government. Establish the lifelong accountability system for ecological responsibilities, combine with the heteronomy and self-discipline of laws and morality and match with the government systems of ecologic performance evaluation, information publication, responsibility list and ecological responsibilities accountability and remedy system.

\section{Construction of the Incentive Mechanism for Ecological Environmental Governance}

Complete the construction of government performance examination indexes and strengthen the efficiency supervision mechanism. Include the ecological governance of officers into the government performance examination system and use the method of government performance index to strengthen the responsibilities of ecological governance and construction. Establish the governance feedback mechanism to supervise the governance feedback of government through the supervision of the public and mass media so as to promote the government to improve the execution and reaction forces and governance efficiency.

Establish the green propaganda and education mechanism and advocate the green living. Normalize the educational curriculums of ecological environmental protection and strengthen the environmental consciousness of the public; increase the investment on environmental protection facilities and flexibly use the public service advertising, texts and other instruments of propaganda to realize the combination of ecological environmental protection and social consensus.

\section{Establishment of Monitoring Mechanism for Ecological Environmental Governance}

Construct the supervision network and establish multiple participation mechanism. Complete the supervision channels: open up hotline for informants, webpage mailbox, WeChat official account and mayor mailbox etc for the citizens and social organizations so that they can participate in the ecological environmental governance. Use the quantity advantage of the public and the advantage of wide contact scope to absorb supernumerary power as the environment supervisors to conduct real-time supervision on the pollution behaviors in living environment and share responsibilities for the ecological environmental governance of government on the supervision attention and execution. Exert the morality constraint force through the public opinion effects of media to build the morality soft power for the ecological environmental governance of the government. Encourage and guide the nongovernmental organizations to conduct the investigation and statistics of ecological environment so as to provide reference for the ecological environmental governance of the government. 


\section{E. Reinforcement of the Execution Mechanism for Ecological Governance}

Implement the execution and operation of ecological governance and establish the execution linkage mechanism. Establish the linkage mechanism of "problem reportgovernance- feedback- supervision" to implement the governance into practice and stress the effectiveness and pragmaticality of governance: realize the optimal governance in the shortest time. Enhance the operation transparency, trace and publish the governance of local pollution accidents to enhance the discloser of information so as to be convenient for the public to execute the supervision and accountability power. Set the comprehensive transregional and cross-basin environmental protection agencies aiming at the ecological environmental governance of the government among regions. Integrate the organization configuration to promote the collective actions among governments and strengthen the assessment and supervision intensity, complete the assessment system and reinforce the system of "regional restricted approval".

\section{F. Establishment of the Ecological Safeguard Mechanism}

Balance the environmental protection and parallel with the economy and perfect the ecological compensation mechanism. Provide economic compensation and medical assistance to the injured party of ecological environment pollution and adjust related interest relationship through economic means. Strictly maintain the ecological red line and avoid the transregional pollution. Increase the intensity of overall planning and promote the construction of environmental protection and poverty relief systems. Complete the subsidy and reward systems through fiscal subsidies system and balance the economic development and environmental protection.

Promote the justification of judicature and complete judicial compensation mechanism. Set environmental protection judicial aid stations to provide methods and guidance of rights protection for the victims. Set out from the administrative enforcement of law, judicature and supervision to perfect the comprehensive assessment system for ecological functions.

\section{CONCLUSION}

The ecological environmental governance is a system engineering which needs the participation of various agencies and departments as well as the improvement of various mechanisms. The construction of governance mechanism can't be accomplished in an action, but needs thorough preparation and long-term adjustment and improvement. The 13th FiveYear Plan provides orientation supporting and idea guidance for the social development and provides basis for the development of various work. The ecological environmental governance is the responsibility of the country and the government and is also the obligation of all social members. The improvement of social participation degree and ecological quality of social members are is the important guarantee of the ecological environment construction of our country. The construction of long-term governance mechanism with sustainable development of ecological environment needs complete theoretical guidance and technical support. Facing the way of sustainable development, it must be rough and we need to advance with the times, adjust the schematic design and cope with changes and challenges of every step. The government should start from its own to update the governing ideas, inherit the green development, set up the ideas of overall situation, reinforce the exchange and cooperation, conduct overall planning to the social mechanism and establish the execution mechanism of "prevention- governancerehabilitation" to lay the favorable and solid foundation for the intergenerational sustainable development.

\section{REFERENCES}

[1] Zhou Wencui, Liu Jingwei, Illusive Establishment and Overcoming of Ecological Responsibilities [J], Academic Exchange, 2016 (1)

[2] Yu Chaowen, Ecological Good Governance of Government from the Perspective of Governance Theory [J], Journal of Anhui Agricultural University, 2013 (1)

[3] Wang Qian, Several Thoughts on the Completion of Ecological Accountability System of The Government with Various Bodies and Diversification [J], Journal of Jinzhong University, 2011 (8)

[4] Ye Jin, Zhou Hongbin, Research on the Construction of Long-term Mechanism for the Ecological Environment Protection for New Countryside [J], Rural Economy, 2009, (3)

[5] Lin Jiancheng, An Na, Study on The Construction of Long-Term Mechanism for Ecological Governance from the Perspective of Modernization of National Governance System [J], Theory Journal, 2015 (3)

[6] Zeng Xiangyun, Study on the Long-Term Mechanism for the Rural Ecological Environment Protection in Tonghua City [J], Environmental Science Trends, 2005 (2)

[7] Peng Xiaoyan, Study on the Compensation Mechanism of Long-term Ecological Environment for the Sustainable Development of Tourism in the Hunan Ethnic Region [J], West Forum on Economy and Management, 2014 (7)

[8] Huang Jie, Zhang Zhenbo, Construction of the Long-Term Mechanism with Multiple Participations for Ecological Governance [J], Journal of Yancheng Institute of Technology, 2015 (3)

[9] Xu Tingting, Shen Chengchneg, Study on the Three Kinds of Dilemma for Ecological Governance of the Government: Idea Difference, Interest Game and Technical Obstacles [J], Jianghai Academic Journal, 2012 (3)

[10] Xiao Jianhua, Deng Jiwen, Dilemma and the Overcoming Methods for Ecological environmental governance $[\mathrm{J}]$, The Journal of Yunnan Administration College, 2007 (1) 